\title{
User Experience at NCR: An Organisational Overview
}

\author{
Phil N. Day \\ Consumer Experience, \\ NCR Corp, Dundee. DD2 4SW \\ phil.day@ncr.com
}

\author{
Graham I. Johnson \\ Advanced Technology \& Research, \\ NCR Labs, NCR Corp, Dundee. \\ graham.johnson@ncr.com
}

\author{
Charlie Rohan \\ Consumer Experience, \\ NCR Corp, Dundee. DD2 4SW \\ charlie.rohan@ncr.com
}

\author{
Chris Riley \\ Consumer Experience, NCR Global Solutions Ltd, \\ Swords, Co. Dublin, Ireland \\ chris.riley@ncr.com
}

\author{
Maggie Carlisle \\ Consumer Experience, \\ NCR Corp, Dundee. DD2 4SW \\ maggie.carlisle@ncr.com
}

\begin{abstract}
In this paper the role of user experience (UX) in a large multinational corporation is presented in an historical perspective with recent organisational changes being described that have resulted in the UX role being placed in a central corporate team. Some examples are selected to illustrate a portion of the activities undertaken by this group, and the skills needed to accompany core technical knowledge are outlined. A working definition of user experience is then described that reflects the recent changes that the user experience role has had in our organisation, with this definition being compared with existing definitions of usability. The paper then concludes with reflections on the UX role within a large organisation, and presents some thoughts on how the UX role could be developed in the future. related context upon individual gaze and action during a collaborative Tetris game. Results show that experts as well as novices adapt their playing style when interacting in mixed ability pairs. We also present machine learning results about the prediction of player's social context.
\end{abstract}

\section{Usability, User experience, Consumer experience, Self-service technology}

\section{INTRODUCTION}

As usability specialists within a large multinational corporation, our role has to be sufficiently broad to serve within the wider organisation.

In this paper we discuss what the user experience (UX) role involves in our organisation and place this in the context of what the role has meant in the past within NCR.

NCR Corporation is a global technology company of 125 years standing, and is headquartered in Duluth, Georgia. NCR's assisted-and self-service solutions and comprehensive support services address the needs of retail, financial, travel, healthcare, hospitality, entertainment, gaming and public sector organizations in more than 100 countries. As a market and technology leader in ATMs (Automated Teller Machines), point-of-sale and checkout technology, and entertainment and airline kiosks, NCR has focussed on the consumer of these publicfacing self-service technologies for many years.

\section{DEVELOPMENT TOWARDS USABILITY IN NCR}

During the late 80's and early 90's NCR Corporation underwent a period of significant expansion in the area of what we now know as UX. This was driven by two central organisations within the US, both having a corporate and therefore an umbrella cross- business role. Previously, industrial designers and engineers had the primary responsibility for ensuring ease of use, applying traditional ergonomics and addressing user-related matters. The HITC (Human Interface Technologies Centre) and Corporate Industrial Design were established in Atlanta GA and Dayton $\mathrm{OH}$ respectively. They created a hub-and-spoke model for what we now call UX, with specialists employed in both centres and the operational businesses elsewhere, such as Dundee, UK and Waterloo, Canada. At that time, the 'usability' role and title within NCR was formally defined as that of Cognitive Engineer in accord with the Zeitgeist.

HITC also embraced the notion of a research and evaluation remit, with adoption of, the then popular, usability lab mentality. The early and mid-90's saw NCR acquired by the US giant, AT\&T. During this period the collaboration with AT\&T Bell Labs became a priority for those concerned with user research with many initiatives aiming to enhance collaboration and exploit fully the well-established research resources with AT\&T.

For many years, the roles of Cognitive Engineer and Usability/HF Engineer were, in line with the times, characterised by those with an applied psychology, 
$\mathrm{HCl}$ (Human-Computer Interaction), human factors or ergonomics research background. The expectation was the systematic, empirical evaluation of proposed, prototype, released and competitor products and ('user') interfaces. At that time, there was a belief in the value of in-house usability labs and they were seen by all as essential to human factors or usability engineering within research and product development. Like many US multinationals, NCR favoured concepts such as task analysis, mental models, ISO 9241-11, and the nirvana of consistency and corporate user interface guidelines $[4,13,22]$. During this time most associates in the general UX domain had skills that were tailored towards evaluation, as opposed to design or requirements capture and definition.

Within the last decade, we have witnessed a fair degree of organizational re-assignment, and the subsequent distribution of design, usability and human factors skills into the business units. Again, efforts were made to ensure co-ordination, method and knowledge sharing. NCR's creation of the London-based Knowledge Lab [21] represented an innovation initiative that focussed upon research using a customer consortium model within which there emerged inter alia a multidisciplinary 'consumer research' team as well as an explicit competency in interaction design.

Further re-organisation and consolidation saw three main teams based in Atlanta and Dundee, with a financial and retail industry scope. This last decade produced the DU+A team (Design, Usability and Accessibility), a consulting team offering human factors expertise to NCR customers, and a research and technology team with $\mathrm{HCl}$ and consumer research as a major focus. These changes served to help shape the techniques and approaches taken. Since the late 90's NCR's user research areas of study have ranged greatly from, for instance, ethnographic investigation $[12,17]$ to technology adoption studies [19, 25].

So, historically NCR, as with many others, has seen a number of changes within those serving to promote the importance of the user or consumer, and has witnessed the gamut of job titles, organisational structures and associated role definitions.

\section{THE CURRENT UX SPECIALIST ROLE AT NCR}

The role of UX specialist at NCR is currently that of an internal subject matter expert, championing the part of the user in our solutions, and offering input and support to multiple parts of the wider organisation as required. This support is given throughout the development process from the initial scoping of requirements through product design, implementation and then rollout. Alternatively the role can be as a subject matter expert in a consulting capability (i.e. UX as a professional service) bringing expertise to solve specific customer needs. This role also includes owning the entire area of 'user experience' from an organisational perspective, with the wider group being expected to provide leadership and direction in terms of the expected experience of the user with a product (including aspects of design, usability and also consideration of product priority as well). Another feature of this role is to champion the accessibility of products by participating in, and supporting those developing standards, and responding to standards. Within the organisation this also involves gaining in-depth knowledge of relevant accessibility regulations, summarising into discrete requirements and advising development and solutions management of these requirements.

Recent changes at NCR have resulted in the UX role being migrated to a central corporate group with a cross-business focus, this group being distributed between Dundee, Dublin and the US. This reorganisation has resulted in a fresh emphasis being placed on UX work, and the remit of the group has been broadened to include a major focus on software thus meaning $\mathrm{HCl}$ (as opposed to traditional ergonomics) skills are also a key requirement for such a role. After these changes were made there was some debate over the appropriate terminology used within the organisation, with job titles including "HCl specialist", "human factors engineer", "usability consultant", "cognitive engineer" and "ergonomist". The decision was taken to use the umbrella term "usability specialist" to cover all these roles, as "usability" was a term that had, and still has, general meaning across the organisation and geographies. The group was also renamed from "Design, Usability and Accessibility" to "Consumer Experience" also known as "Cx" to reflect this broader remit. This multidisciplinary group also includes interaction designers and industrial designers thus enabling UX input to be involved right from the start of any new design work, and allowing for the complementary skill sets from the design discipline to enrich the UX function. A related professional services group within NCR has similarly been renamed from "Human Factors Engineering" to "Consumer Experience Consulting".

The UX role now considers usability and accessibility issues for hardware and software products and related tools for multiple business units within the company. A particular focus is in the area of walkup and use self-service terminals that can be used by anyone, at any time, anywhere, and also many diverse professional and self-service applications delivered through desktop, kiosk, mobile and internet channels. An essential component of such a role is an appreciation of the design and usability challenges of complex technologies in the public domain for 
both able-bodied and disabled user groups across international populations and how they are to be prioritized with other engineering, market and cost considerations. Typically this involves working in a distributed, multidisciplinary project team including interaction designers, industrial designers, solutions managers, sales personnel and hardware and software engineers.

\subsection{The Usability Role in Practice}

A number of practical examples are selected from the wide variety of usability activity undertaken by the group in order to give a greater insight into what this role involves.

\subsubsection{Expert Review of Hardware Consumer Usability}

An expert usability review is often conducted at a very early stage in the development of a new product or module and typically includes aspects of consumer usability and accessibility. This can, at an early stage in product development, be at a rather coarse level with the model consisting of a simple space volume and some approximate positions for interface elements. A key tool that is often utilised for this type of review is to take the early concept model from CAD into a human modelling software application (such as SAMMIE for example), and use this to rapidly assess reach and visibility issues on the proposed product layout [15].

As the development matures, an early engineering build of the product enables further reviews to be conducted. These reviews can include using an in-house checklist containing key usability and accessibility requirements such as maximum allowable force and grips accommodated for insertion or removal of media, acceptable height ranges for the interface and sample eye heights to quickly validate visibility for worldwide populations. In addition, this type of review typically involves walking through frequently completed consumer tasks (such as transferring money or withdrawing cash at an ATM). A further portion of this activity includes assessing compliance to accessibility regulations. This type of product review is then used as the basis for sign off at two key milestones: the first of these on completion of the product development, and the second on completion of the manufacturing phase of the product. Sign-off is commonly completed with accessibility issues and non-compliances being separated from general usability issues.

\subsubsection{Expert Review of First Line Maintenance Usability}

An expert review of usability of a product for replenishment and maintenance users is also often conducted at the early stages in product or module development. This involves assessing whether visibility and access to all portions of a product or module is sufficient for a number of first line maintenance tasks (such as jam clearance and replenishment of media such as receipt paper or cash in an ATM). These tasks often force certain postures (bending, stooping, lifting cassettes or paper rolls) and therefore some assessment of the space volume that is therefore needed in order to replenish and service the product or module is required. (This space volume is commonly referred to as a service footprint.) Again, we have found the use of human modelling software to be valuable in this, with approximate space volumes for modules in the product quickly being imported and then human models being used to evaluate reach and visibility. In addition, the human models are placed in the postures needed to complete the tasks thus the volume needed is defined by these postures. This initial analysis is then validated later in the development lifecycle with first line maintenance task walkthroughs being conducted on an early development build to ensure that the service footprint previously identified definitely allows all tasks to be completed.

\subsubsection{Usability Study of Novel Device Performance} Often a novel device or module is to be investigated before integration into an existing product. One recent example comes from the integration of a biometric authentication system into our self-service products [26]. The use of biometrics technology, such as fingerprint recognition, poses a number of unique challenges. Finger placement problems are an issue as people are either unfamiliar with the technology or negative transfer leads people to roll or swipe their finger across the device when a static finger placement is required. Compounding this problem a high quality image must be captured during enrolment (the first time people use the device) or the accuracy of all subsequent authentications will be impaired.

To address these issues the user interface to support biometrics was re-designed. Following a participative design process, a number of competing approaches to the representation of the graphical lead through and feedback emerged. A user trial was conducted to evaluate these different approaches and the alternative designs were compared (Figure 1). This participative design and evaluation approach allowed us to understand how people approached this relatively new technology and distinguish between competing designs. The design guidelines from this work were used to 
inform the development of biometric authentication as an NCR-supported offering.
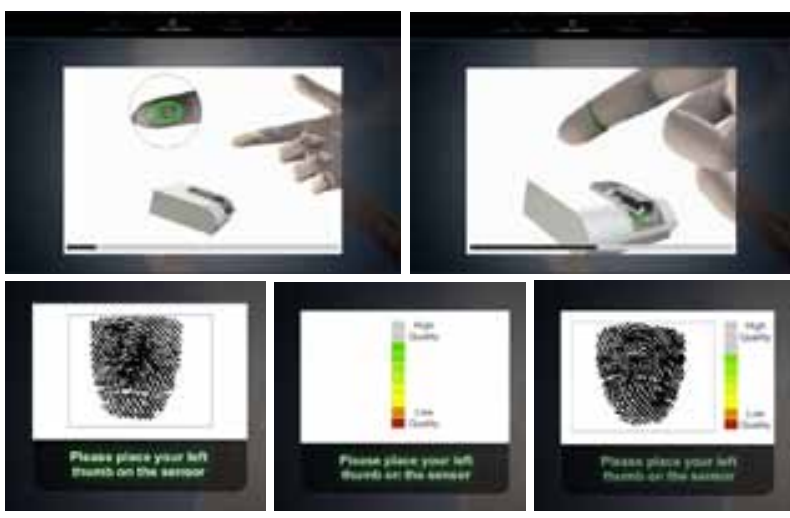

Figure 1: Images of lead-through and feedback designs tested

\subsubsection{Usability Study of a New Hardware Design} In this type of study a new product range has typically been completed, and therefore a usability study with members of the general public is required; an example of this was conducted just over a year ago. This study, with 100 participants, focused on three main features that had not been previously assessed; namely a biometric fingerprint reader, a contactless card reader, and a bulk cheque deposit module (Figure 2). A representative sample of ages, heights, and genders were recruited. The lead through used in this study was developed from the findings of the previously mentioned biometrics study. In addition, as it was suggested that biometric performance degrades with age, the sample included a large number of participants over the age of $65(22 \%)$.
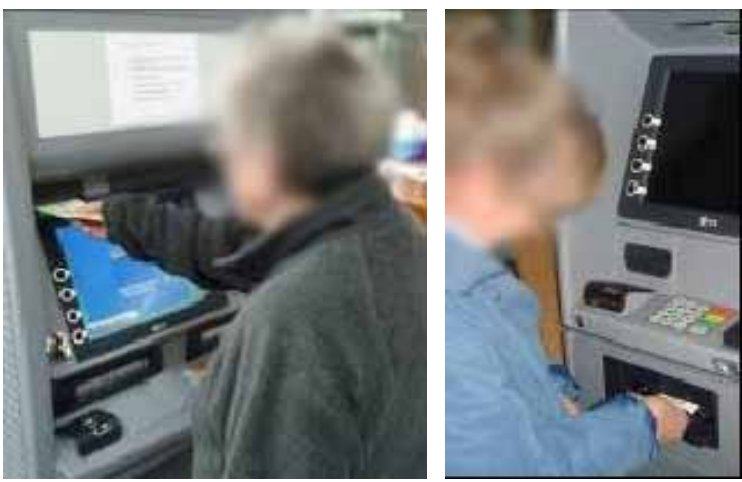

Figure 2: Images from recent ATM usability study

Another example of a larger usability study like this investigated a drive-up ATM product which considered the reach to different elements in this very constrained environment [16].

\subsubsection{User Interface Design and Evaluation}

In this type of activity, common when working on software projects, work commences early in the software development life cycle. For instance, on a current large software project, engagement began with a period of requirements gathering.
This requirements gathering exercise included fieldbased observations and clarification of reported requirements with potential end- users. Once requirements had been refined paper prototypes (of the user interface) were sketched then used to further refine the requirements, with these sketches then being developed into wireframes. Heuristic reviews of the existing development build of the software were conducted in parallel with this early design phase. A visual strategy was defined which incorporated how the brand applied across the overall look and feel of the product, and then the detailed designs were produced. It is important to note that these designs involved extensive collaborations between interaction designers and usability specialists, with reviews and walkthroughs being conducted on a daily and sometimes hourly basis. The final designs are produced in such a manner that the visual assets can be referenced directly in the code, thus reducing potential mismatch between the original design and the final implementation, in addition to streamlining this handover process. A plan has also been defined to continue this engagement as a phased iterative approach to future developments, and for a large scale usability test to be conducted with multiple end user groups in multiple geographical sites. In this type of project, the next stage would have changes being submitted formally as requests for change from any such review, with these changes then feeding into future development phases. Other smaller engagements have included designing software for bank staff to manage cash, and an early banking application for mobile telephones (Figure 3 ).
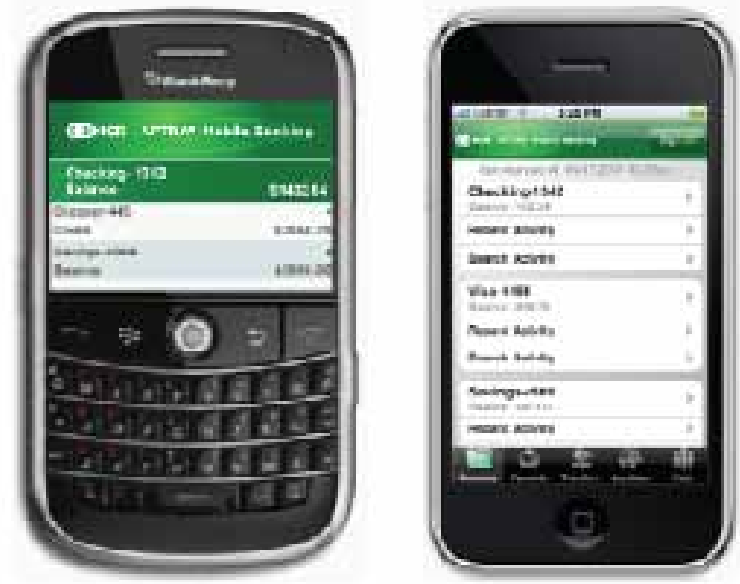

Figure 3: Designs for mobile banking application

\subsubsection{Conceptual Design Work}

In contrast to the previously outlined evaluative approach of existing products or modules, some of our engagements occur very early before requirements for a product have been set. Often visual concepts are found to be a valuable aid to this early exploratory activity, in the form of sketches or renders. These visual concepts, produced by 
designers with input from usability specialists, show the design of possible directions for new products or product themes and are used to promote discussions and begin an engagement with a customer. Often these early exploratory activities then result in a longer term engagement with the team, as key information is elicited by means of a number of visual concepts being available to refine and focus thinking. The visual appeal and innovative aspects of these concepts are often important in the beginning of this engagement, sometimes more so than the finer detail of the usability benefits of such a concept.

\subsubsection{Accessibility, Inclusive Design and Compliance}

An additional element of the UX role in our organisation is considering issues of accessibility. This is true for both the hardware and software portions of the business. In the software space, much of the regulation is tending to converge on version 2.0 of the W3C's Web Content Accessibility Guidelines [2]. However, in the hardware space, there is a wide variety of regulations, with some countries having laws (e.g. the US ADA [3]), others having standards (e.g. Canada [8] and Brazil [7]), and other having guidelines (e.g. UK [5] and Australia [6]). Many of these regulations are included within those aspects of making buildings accessible and tend to focus on making self-service terminals such as ATMs accessible to those in a wheelchair or with visual impairments. Although there is some common ground between many of the regulations, there are sufficient differences to ensure that each countryspecific regulation has to be carefully considered. One of the challenges of this is to carefully balance the requirements driven from accessibility regulations with the requirements of the general population. For example, accessibility regulation enforces the interface being between certain heights, and below a maximum height. However, this can compromise the usability of the terminal particularly for the taller standing population and therefore trade-offs must be made.

In addition to considering compliance with regulations, the role also includes going beyond the standards in terms of input to future standards and conducting expert reviews from the perspective of consumers with specific impairments. For example, the ability of consumers with reduced manual dexterity to insert and remove media from a terminal is often considered, typically by walkthroughs with different hand grips and simulated manual dexterity problems. In a similar manner, legibility of labels and on-screen instructions can be assessed using simulated reduced visual acuity. Finally, we have also found the use of SAMMIE useful in this regard as well, particularly when used in conjunction with the HADRIAN dataset [11]; namely by evaluating reach, visibility and grip issues for a human with specific joint constraints.

\subsection{Oft-overlooked Skills for Usability}

Rather than attempt a comprehensive list of skills needed for UX professionals derived from the Ergonomics, $\mathrm{HCl}$ and Psychology disciplines, this section focuses on skills that are often omitted from such lists, but we have found to be invaluable in our professional experience within NCR.

Skills that are required to represent and exert significant influence within a large organization driven by other priorities are of high importance. We have found that a considerable amount of time is spent in being an advocate for the UX function, and this ability, of evangelising and encouraging other parts of the organization to engage with the UX role, is necessary to not only sustain the UX role, but also to bring value to the wider organisation. This is particularly important as our UX role is a small group in a much larger organization. To a significant extent the impact of the group is influenced by the credibility that the group has within the organization; to this end presenting summary information of current activity (especially up to the executive level) and promoting successful engagements is also an important function within the group.

Related to this skill of persuasion is the role of informing others and raising awareness within the organization, not just as to the merits of UX in the abstract, but to the real-world impact that such engagement has had in previous programs. In addition, we have found that a solid understanding of other disciplines and well-developed negotiation skills are also called upon, as is an element of political maturity in dealing with disparate parts of the organization and their different priorities.

These skills have been of importance in handling the occasional adversity or misunderstanding that comes with working in a large organisation; this adversity is significantly reduced when there are a number of senior people within the organisation who understand both the importance and the value of the user experience role. Building trust and a proven track record within the organisation has been instrumental in our group gaining a number of these internal 'allies' both before and after re-organisation. The ability to provide effective, visual summaries of complex issues and results is also very valuable, as is producing concise, actionable recommendations. In one example, a significant amount of statistically significant data had been obtained that clearly indicated the need to radically alter the layout of a product interface. However, it was only when this data was summarised in terms of coloured 'zones' of reach that all internal stakeholders were convinced of this need.

We have found human modelling software and also 
graphical summaries of information to be useful in this regard (and indeed some of these visual summaries have then been used in marketing collateral for our products). Although statistically significant results have great resonance for scientific colleagues, a visual summary can be more readily perceived by all, and is therefore a more powerful tool in informing and persuading the wider organisation of findings and recommendations.

Finally the ability to apply theoretical knowledge to novel and unexpected areas is an additional required skill as our day to day experience shows that input is often sought across many diverse application areas. Having the fundamental knowledge, say of perception and human performance, is essential in being able to explain and justify recommendations. As mentioned earlier, the ability to articulate these views to decision-makers is also critical.

\section{USER EXPERIENCE DEFINED}

In the previous section we have presented some examples of what the UX role involves at NCR. However, we have also been wrestling with issues of definition as the popularity of terms such as user experience has taken hold. As previously mentioned, the organisational changes have resulted in our group now being referred to as the Consumer Experience group, and we have therefore had to invest some time into working through what this might mean.

ISO 9241-11 [4] defines usability as 'the extent to which a product can be used by specified users, in a specified context of use, to achieve specified goals with effectiveness, efficiency and satisfaction' (emphasis added). This is updated slightly in FDIS 9241-210, but the main definition remains essentially unchanged.

In addition ISO final draft FDIS 9241-210 defines user experience as:

'A person's perceptions and responses that result from the use and/or anticipated use of a product, system or service (emphasis added).' [1]

Both definitions imply that usability and user experience are measurable. Indeed Bevan suggests that 'perceptions and responses' can be equated with the notion of satisfaction in usability and user experience can therefore be accommodated within the previous three-element definition of usability [9]. Another relevant discussion is contained within a survey of the community from $\mathrm{CHI} 2009$. This survey found that there was a broad body of opinion on what user experience might mean, but concluded that the 9241-201 definition was in line with their results [20]. They also specified that user experience:

'focuses on interaction between a person and something that has a user interface.'

One key component that the popular appeal of user experience seems to have brought is an awareness of aesthetics and engagement related to products or services. This has helpfully been referred to by Norman as emotional design, with products appealing not only on the behavioural level (which can be mapped onto effectiveness and efficiency of use) and the reflective level (mapping onto satisfaction), but also on the visceral level [24]. Norman suggests that this visceral level can be thought of as mapping to the appearance of a product. Bevan also suggests a similar theme; that of a different emphasis between task performance (usability) and pleasure (user experience), and also notes the longitudinal nature of user experience from expectation, interaction with the product, and subsequent reflection on the experience. This theme is also explored by Hassenzahl \& Tractinsky who suggest the facets of user experience are the experiential, emotion and affect, and what they call 'beyond the instrumental' i.e. holistic and aesthetic issues [18]. Their interesting conclusion is that we should be 'designing for pleasure, rather than for absence of pain'.

Although this is helpful, it is difficult to define or measure this attribute of pleasure or appearance. We have found it useful to begin looking at the interaction between the creative design disciplines (such as Industrial and Interaction Design) and the analytical disciplines (such as usability engineering or $\mathrm{HCl}$ ). This can help to better define the additional elements that UX can be said to encompass. Many of the 'design-led' or 'design-thinking' methodologies bear significant similarities with a human-centred approach with an emphasis on the entire experience. For instance, Brunner et al. (2008) postulate that 'design-driven companies focus on people throughout the process. ... It all comes from the idea of creating an emotional response.' [10] They further suggest that a product is not just an object. Instead, they promote the view that products or services 'become an icon and a venue, a doorway or portal for a specific community to a unique experience.'

More controversially they also consider successful consumer products such as the Apple iPod personal music player and the Garmin Nuvi GPS device, and state that

'You have to get beyond usability for great design.

It has to be desirable too.'

They justify this by stating that with many of these products, there are minimal instructions, and people are expected to pick it up and play with it. The initial desirability and engagement are therefore important in interacting with, and learning about, the product. A working definition of user experience that may be 
helpful is to consider user experience as a superset of usability adding a fourth attribute to the previous list. We therefore suggest that such a definition could be

\begin{abstract}
User experience is a person's perceptions and responses that result from the use and/or anticipated use of a product, system or service, where these perceptions and responses can be characterised in terms of effectiveness, efficiency and satisfaction in achieving specified goals, and also in terms of an engagement with the product, system or service.
\end{abstract}

This addition of engagement matches Mayhew's idea of "persuasion architecture" being an addition the user experience role [23]. This importance of clearly stating the value proposition of work, and providing actionable recommendations (or 'calls to action' in Mayhew's terms) is something that we have found to be very important in working with internal and external stakeholders. In fact, these ideas of engagement and persuasion are, in our view, two sides of the same coin, with engagement referring to the relationship between an end-user and a product, system or service, and persuasion referring to a the relationship between an internal stakeholder and a product, system or service (i.e. the engagement of an internal stakeholder). Adding this engagement element to user experience therefore also encompasses the aforementioned skills of influence, persuasion and communication, both in developing our role as specialists, and in working with those from other disciplines within an organisation such as marketing or solutions management. This type of approach is also reflected in what IBM have reported as their User Engineering model of user experience, with a key stage being defining what the market wants and needs [27].

This perspective has also been helpful in persuading senior executive level leadership of the importance of the consumer experience group, and has resulted in greater buy-in from these executives. This has been evidenced in the change in position of the group both in terms of a corporate, cross line of business focus, and in reporting directly to a high level executive.

As a result of this refinement of the user experience role we have found a slight change in focus, rather than in skills. This has sometimes meant a reduction in the scope of some studies to investigate areas that would lead to actionable results that add to the previously defined value proposition of a product. In other cases this has involved doing the same empirical work as described earlier in this paper, but paying more attention to the communication and feedback of the results to internal stakeholders.

On a related point, this broadening of focus to also consider the engagement of internal stakeholders with a product has also resulted in some work that blurs the boundaries between marketing and user experience functions. For example, recent work on a mobile banking interface not only focused on the usability of the interface, but also how the corporate brand was to be applied to this type of interface, and how we could make a somewhat prosaic financial transaction more visually appealing and compelling (Figure 3).

\section{CONCLUSIONS}

Our experience suggests that the UX function within a large organisation has to be pragmatic enough to work within the constraints of the larger organisation including cost, schedule and business priorities. One key to this as previously mentioned is to inform other parts of the organisation of UX principles, and to embed UX knowledge in the form of testable requirements. An added benefit of this approach is to reduce the load on the UX team as others in the organisation can then implement and test these requirements.

The degree to which UX can exert its influence over the direction and shape of a specific program of work within research and development is formally determined by those processes which are applied. Without being attached to and grounded in the key processes, the UX role can be frustrating as it will be seen as tangential. The importance of sign-off, contribution to formal approvals and an enforced involvement in the development process is necessary at a basic level. More importantly, however, the appreciation of UX and what it can bring to a product development is typically subject to individual decision-makers, stakeholders and major teams.

We have found that an engineering focused company it has generally easier to influence to improve accessibility and ensure compliance with relevant standards and regulations. Pushing for changes based on improved usability can be a harder sell, though there the concept and terminology of 'usability' is sufficiently infused within the organisation that agreement can be reached. In general, arguing for changes based on the user experience or engagement is a tougher sell still. This newer, more loosely defined idea takes longer to permeate thorough a large organisation. However, UX must be perceived as essential role in the development of successful products if there is to be full collaboration and engagement with the relevant process elements.

Upon reflection of the development of UX and usability roles within NCR, one clear conclusion that we can draw, is the requirement to move with the times, demonstrating flexibility within a large organisation, and simultaneously with respect to evolving technologies. The latter relates not only to 
those technologies determining products, service and user experiences, but also the tools with which we carry out the UX function.

Working within and for a large, global organisation also brings with it several challenges that are not unlike those faced when engaging a distributed customer from a consultancy base. The need to articulate value concisely, to achieve rapport with other project members, and to master the art of collaboration are key skills. The question of collaboration is also pertinent to the emerging nature of UX as a discipline. We must look to a future where under the umbrella of the UX title we see specialists with many and varied core skills, whether in animation, ethnography, applied psychology, ergonomics, prototyping or the variants of contemporary design approaches. The relationship between these diverse skills is a crucial step towards extending and enriching what is meant by the UX role.

It may also be beneficial for the discipline as a whole if an agreed definition of user experience can be produced, potentially in future releases of international standards. This would have the double benefit of reducing potential confusion and also raising the profile of this new term.

\section{ACKNOWLEDGMENTS}

This paper is based upon material that was previously presented at UXCF2010 - The 1st User Experience Competency Framework Workshop, which was jointly organised by the BCS Interaction Specialist Group and the UK chapter of the Usability Professionals Association [14].

We are grateful to NCR Corporation and to our colleagues in the Consumer Experience, Consumer Experience Consulting and NCR Labs teams for their support.

\section{REFERENCES}

[1] ISO FDIS 9241-210 Human-centred design process for interactive systems.

[2] Web Content Accessibility Guidelines (WCAG) 2.0.

[3] ADA Standards for Accessible Design, 28 CFR Part 36, July 1994.

[4] ISO 9241-Part 11: Guidance on usability. Ergonomic requirements for office work with visual display terminals (VDTs), 1998.

[5] Access to ATMs: UK Design Guidelines (Centre for Accessible Environments), 2002.

[6] Australian Bankers' Association (ABA) Industry Standard, Automatic Teller Machines (ATMs), 2004.

[7] ABNT NBR 15250, Acessibilidade em caixa de autoatendimento bancário (Accessibility in automatic teller machines), 2005.
[8] CAN/CSA B651.1-07 Barrier-Free Design for Automated Banking Machines, 2007.

[9] N. Bevan. What is the difference between the purpose of usability and user experience evaluation methods? In UXEM'09 Workshop, INTERACT 2009, Uppsala, Sweden, 2009.

[10] R. Brunner, S. Emery, and R. Hall. Do You Matter? How Great Design Will Make People Love Your Company. FT Press / Pearson Education, Inc., New Jersey, 2008.

[11] K. Case, R. Marshall, D. Hogberg, S. Summerskill, D. Gyi, and R. Sims. HADRIAN: Fitting trials by digital human modelling. In V. G. Duffy, editor, Digital Human Modeling, LNCS-5620, Second International Conference, ICDHM 2009, Held as Part of $\mathrm{HCl}$ International 2009, San Diego, CA, USA, pages 673-680. Springer, July 2009.

[12] L. Cooper, G. I. Johnson, and C. Baber. Inside the consumer's wallet: An ethnographic enquiry. In S. Brewster, A. Cawsey, and G. Cockton, editors, INTERACT '99, Proceedings of International Conference on Human-Computer Interaction, volume 2. IOS Press, Kluwer, 1999.

[13] L. Coventry, G. I. Johnson, and M. G. Westwater. Usability engineering at NCR. In M. A. Sasse, R. J. Cunningham, and R. L. Winder, editors, People and Computers $\mathrm{XI}$ : Proceedings of $\mathrm{HCl}$ (HumanComputer Interaction) '96, London, UK, 1996. BCS $\mathrm{HCl}$, Springer-Verlag.

[14] P. N. Day, G. I. Johnson, C. Rohan, M. Carlisle, and C. Riley. An NCR perspective on UX competency. In UXCF2010 - The 1st User Experience Competency Framework Workshop (BCS Interaction Specialist Group and the UK chapter of the Usability Professionals Association). BCS / UPA, 2010.

[15] P. N. Day, C. Riley, C. Rohan, S. J. Summerskill, and R. Marshall. Use of human modelling software in a commercial design environment: a SAMMIE CAD case study. In Proceedings of the Institute for Ergonomics and Human Factors Annual Conference 2010, 2010. In press. [

16] P. N. Day, C. Rohan, L. Coventry, G. I. Johnson, and C. Riley. Reach modelling for driveup self-service. In Proceedings of the Institute for Ergonomics and Human Factors Annual Conference 2010, 2010. In press.

[17] A. De Angeli, U. A. Athavankar, A. Joshi, L. Coventry, and G. I. Johnson. Introducing ATMs in India: A Contextual Enquiry. Interacting with Computers, Special issue - Global human-computer systems: Cultural determinants of usability, 16(1):29-44, 2004. [

18] M. Hassenzahl and N. Tractinsky. User experience - a research agenda. Behaviour and Information Technology, 25(2):91-97, March-April 2006. 
[19] G. I. Johnson and L. Coventry. You talking to me? Exploring voice in self-service user interfaces. International Journal of Human-Computer Interaction, 13(2):161-186, June 2001.

[20] E. L.-C. Law, V. Roto, M. Hassenzahl, A. Vermeeren, and J. Kort. Understanding, scoping and defining user experience: A survey approach. In Proc. Human Factors in Computing Systems, CHI'09. April 4-9, 2009, Boston, MA, USA, pages 719-728, 2009.

[21] P. Lynch, S. J. Emmott, and G. I. Johnson. The NCR Knowledge Lab. In S. Brewster, A. Cawsey, and G. Cockton, editors, INTERACT '99, Proceedings of the International Conference on Human-Computer Interaction, volume 2, pages 229-230. IOS Press, Kluwer, 1999.

[22] T. J. MacTavish. The NCR Human Interface Technology Center. In CHI '97 Proceedings of the 1997Conference on Human Factors in Computing Systems, NY, 1997. ACM's Special Interest Group on Computer-Human Interaction (ACM/SIGCHI), ACM Press.

[23] D. J. Mayhew. User experience design: The evolution of a multi-disciplinary approach. Journal of Usability Studies, 3(3):99-102, May 2008.

[24] D. A. Norman. Emotional Design: Why we love (or hate) everyday things. Basic Books, Cambridge, MA, 2005.

[25] C. Riley, K. Buckner, G. I. Johnson, and D. Benyon. Culture and biometrics: Regional differences in the perception of biometric authentication technologies. Al \& Society, Special Issue: Enculturating Human-Computer Interaction, 24(3):295-306, October 2009.

[26] C. Riley, G. I. Johnson, H. McCracken, and A. Al-Saffar. Instruction, feedback and biometrics: The user interface for fingerprint authentication systems. In T. Gross, J. Gulliksen, and P. Kotzé, editors, Human-Computer Interaction INTERACT 2009, volume 2, pages 293-305, Heidelberg, 2009. IFIP (International Federation for Information Processing) TC 13, Springer.

[27] K. Vredenburg. Building ease of use into the ibm user experience. IBM Systems Journal, 42(4):517531,2003 . [26] K. Vredenburg. Building ease of use into the ibm user experience. IBM Systems Journal, 42(4):517-531, 2003. 